\title{
AOR
}

Selected Papers of \#AolR2021:

The 22nd Annual Conference of the:

Association of Internet Researchers:

Virtual Event / 13-16 Oct 2021

\section{Towards a Multi-Dimensional Theory of Temporal Control in the Gig Economy}

\author{
Chi Kwok \\ Lingnan University, Tuen Mun, Hong Kong, China
}

Ngai Keung Chan

The Chinese University of Hong Kong, Sha Tin, Hong Kong, China

\section{Introduction}

The last decade has witnessed a skyrocketing growth of the gig economy that relies on algorithmic technologies to manage and organize work (Chen \& Sun, 2020; Rosenblat, 2018; Shapiro, 2018). Time and space, meanwhile, are central to the organization of gig work due to its "on-demand" nature. On the one hand, labor platforms promise to liberate gig workers from traditional bureaucratic labor markets through flexibly scheduling. On the other hand, platforms rely on algorithms to direct and monitor workers' spatial movement. Highlighting the spatial triad of algorithmic surveillance, Newlands (2020) argues that food delivery platforms rely on conceived space (i.e., abstract spatial representations generated by data such as digital maps) to exercise labor control, while ignoring workers' lived experiences. As such, workers' spatial agency is constrained by algorithmic management and information asymmetries (Barratt et al., 2020).

While much has been written about platform-based spatial control, the temporalities of labor control in the gig economy remain under-theorized. As Chen and Sun (2020) contend, "this research gap is somewhat ironic when considering the temporal dimensions connoted by terms like "on-demand service" and the "just-in-time" labor force" (p. 1563). Chen and Sun introduce the notion of "temporal arbitrage" to capture how Chinese food couriers work in a fragmented and often opportunistic manner to meet customers' temporal expectations. Indeed, workers can experience time differently due to their economic and social status (Gregg, 2011; Sharma, 2014; Wajcman, 2015) as well as platform-based socio-technical infrastructures.

This paper proposes a multi-dimensional theory of temporal control in the gig economy. Specifically, we focus on different types of platform-based temporal control and respective effects on workers' autonomy, value of free time, and their social and political

Suggested Citation (APA): Kwok, C., and Keung Chang, N., (2021, October). Towards a Multi-Dimensional Theory of Temporal Control in the Gig Economy. Paper presented at AolR 2021: The 22nd Annual Conference of the Association of Internet Researchers. Virtual Event: AolR. Retrieved from http://spir.aoir.org. 
connectedness. Theoretically, we draw on the sociology of time (Thompson, 1967; Wajcman, 2015) and normative time literature in political theory (Goodin, 2019; Rose, 2016). Empirically, the framework is primarily informed by the synthesis of the literature about algorithms in the gig economy, with particular attention to the methods of temporal control. Meanwhile, we draw insights from a larger comparative project that examines algorithmic labor control and resistance across ride-hailing platforms (Uber and Lyft), TaskRabbit, and delivery platforms (DoorDash, Uber Eats, and Instacart) in the United States. The project interviewed 50 gig workers between 2017 and 2020.

This paper contributes to understanding temporalities and work autonomy in the gig economy, and more broadly, flexible workplaces where the boundaries between work and non-work time become blurred (Gregg, 2011).

\section{Towards a Multi-dimensional Theory of Temporal Control}

Below we briefly explicate the four components of the multi-dimensional theory of temporal control: (a) autonomy, (b) value of free time, (c) competitive vulnerability, and (d) opportunities for social and political participation.

The first component is autonomy. Temporal resources are a necessary condition of autonomy, meaning that the amount of time available for discretionary control defines one's relative degree of freedom (Goodin, 2009). Within the context of the gig economy, temporal autonomy has to do with (a) what actionable information is available to workers when accepting an order; and (b) how labor platforms incentivize workers to accept tasks. For example, delivery platforms may withhold drop-off information from workers, rending workers to evaluate whether an order is worthy of their time and labor. Additionally, ride-hailing platforms may rely on their algorithmic pricing system and techniques of gamification to incentivize drivers work in a particular area and time period (Rosenblat, 2018).

The second component is the value of free time. Anderson $(2017$, p. 136) calls the short duration of free time available between two job duties "unpaid junk time". Short intervals between multiple on-demand duties are common in the gig economy, while free time structured in such way can hardly be utilized meaningfully. For example, the interview data shows that TaskRabbit workers tended to avoid scheduling back-to-back appointments, partly because clients could request for changes in the task at the last minute. As one of the interviewees shared, "I'll try to schedule my clients with a little bit of a buffer between, but I also want to maximize how many jobs I'm working in a day ... I don't want to be standing around for an hour doing nothing." The "free" time in between appointments is unpaid yet necessary for workers to maintain their employability on the platform.

The third component is competitive vulnerability. Workers' vulnerability is exemplified in their need to comply with the design of the temporal system as well as unpredictable customer demand. In other words, they have to constantly adjust their temporal arrangements in order to fit others' expectations. Chen and Sun (2020) argues that "the combination of the visibility of the wait time and the expectation of on-demand service can lead customers to rush the rider or to cancel the order" (p. 1568). Our interview 
findings also show that waiting is an essential part of ride-hailing and delivery drivers' work experiences. Platforms, meanwhile, deploy algorithmic metrics (e.g., on-time/early rate on DoorDash) to punish workers who fail to meet the estimated time of arrival. Workers are placed in a vulnerable position to rationalize customer-oriented temporal expectations.

The fourth component is social and political participation. Non-standard work hoursincluding weekend work-is a common feature of the gig economy. Rose (2016) has shown that collective actions require collective free time, and collective free time is free time that members of the society know that one another would be collectively free. This component critically assesses (a) how scheduling practices may disrupt such temporal coordination in the gig economy and (b) how workers attempt to overcome individualization during their work and non-work hours (Tassinari \& Maccarrone, 2020).

Overall, we aim to highlight the different aspects of wrongs and injustices workers experienced in prevalent forms of temporal control in the gig economy.

\section{References}

Anderson, E. (2017). Private government: How employers rule our lives (and why we don't talk about it). Princeton University Press.

Barratt, T., Goods, C., \& Veen, A. (2020). 'I'm my own boss...': Active intermediation and 'entrepreneurial' worker agency in the Australian gig-economy. Environment and Planning A: Economy and Space, 52(8), 1643-1661.

Chen, J. Y., \& Sun, P. (2020). Temporal arbitrage, fragmented rush, and opportunistic behaviors: The labor politics of time in the platform economy. New Media \& Society, 22(9), 1561-1579.

Goodin, R. E. (2009). Temporal justice. Journal of Social Policy, 39(1), 1-16.

Gregg, M. (2011). Work's intimacy. Polity.

Newlands, G. (2020). Algorithmic surveillance in the gig economy: The organization of work through Lefebvrian conceived space. Organization Studies. Advance online publication. https://doi.org/10.1177/0170840620937900

Rose, J. (2016). Free time. Princeton University Press.

Rosenblat, A. (2018). Uberland: How algorithms are rewriting the rules of work. University of California Press.

Shapiro, A. (2018). Between autonomy and control: Strategies of arbitrage in the "ondemand" economy. New Media \& Society, 20(8), 2954-2971.

Sharma, S. (2014). In the meantime: Temporality and cultural politics. Duke University Press. 
Tassinari, A., \& Maccarrone, V. (2020). Riders on the storm: Workplace solidarity among gig economy couriers in Italy and the UK. Work, Employment and Society, 34(1), $35-54$.

Thompson, E. P. (1967). Time, work-discipline, and industrial capitalism. Past \& Present, 38(1), 56-97.

Wajcman, J. (2015). Pressed for time: The acceleration of life in digital capitalism. The University of Chicago Press. 